\title{
Lifestyle and Cancer Prevention-Opinions and Behaviors Among Romanian University Students
}

\section{Lucia Maria Lotrean \\ Mira Florea (ID) \\ Codruta Lencu}

Faculty of Medicine, luliu Hatieganu University of Medicine and Pharmacy,

Cluj-Napoca, Romania
Correspondence: Mira Florea

Email miraflorea@umfcluj.ro
Background: Healthy lifestyle promotion represents an important component of cancer prevention. The aim of this study is the assessment of opinions and behavior related to healthy lifestyle and cancer prevention among Romanian university students.

Methods: A cross-sectional study was performed by anonymous questionnaires in 2017 among 400 university students from the four main universities from Cluj-Napoca, Romania. Results: One out of five students was overweight or obese, but $83 \%$ meet the recommendations for performing physical activity. The majority did not meet the recommendations of eating $400 \mathrm{~g}$ of fruits and vegetables daily, while almost half declared eating more than 500 $\mathrm{g}$ of red meat weekly and more than one third do not respect the recommendations for alcohol consumption. The factor analysis reveals two factors with regard to cancer prevention-related behaviors. The first one consists of those having an appropriate body weight, and having a higher tendency for consumption of fruits and vegetables, performing physical activity, while being more prone not to respect the recommendations regarding the alcohol consumption. The second factor refers to a higher tendency to respect both the recommendations for alcohol and red meat consumption.

Conclusion: Future educational activities should focus on promoting better nutritional habits, decrease alcohol consumption and offer appropriate services for weight management among Romanian university students.

Keywords: nutrition, physical activity, students, cancer prevention

\section{Introduction}

Healthy lifestyle promotion represents an important component of cancer prevention. ${ }^{1,2}$ The World Cancer Research Fund (WCRF) and American Institute for Cancer Research (AICR) published Diet, Nutrition, Physical Activity, and Cancer: A Global Perspective, the WCRF/AICR second expert report in 2007 and it was revised and updated as the third report published in 2018. ${ }^{3,4}$ The reports contain recommendations and, as underlined by an expert panel that authored these recommendations, each of them was intended as one part of a comprehensive package of modifiable lifestyle behaviors which together, promote a healthy pattern of diet and physical activity which help the prevention of cancer, but also noncommunicable diseases, and obesity. ${ }^{4,5}$

Recently the $2018 \mathrm{WCRF} / \mathrm{AICR}$ Score, (a practical tool that operationalizes eight of the ten $2018 \mathrm{WCRF}$ /AICR cancer prevention recommendations), proposed maintaining a healthy body weight, adoption of an active lifestyle, consumption of a diet rich in whole grains, vegetables, fruit and beans, limit consumption of "fast foods" and other processed foods high in fat, starches or sugars, limit consumption 
of red and processed meat, limit consumption of sugarsweetened drinks, limit alcohol consumption, and (optional for mothers) breastfeed your baby, if you can. The tool is structured in such way that higher score reflects greater adherence to the recommendations. ${ }^{5}$ It is emphasized that the implementation of this standardized score in epidemiologic and clinical studies will enhance comparability of findings across populations and countries. ${ }^{5}$

In recent years several studies investigated the knowledge, attitudes and practices with regard to cancer prevention recommendations among adults from different countries, including one study which investigated these issues among Romanian adults having relatives with cancer. $^{6-12}$ There are also recent studies which used the 2018 WCRF/AICR Score. ${ }^{13-15}$

Several studies investigated knowledge, attitudes and behaviors related to dietary habits, physical activity and cancer prevention among the younger population such as university students, but to the best of our knowledge no study used the 2018 WCRF/AICR Score, which focuses on promoting a healthy diet across the lifespan, favorable to the prevention of different types of cancer as well as other chronic diseases. ${ }^{16-21}$ University students transit a life period when they become more independent, have a busy schedule, maybe even live apart from their parents, and hence being responsible for choosing, buying and cooking their food, deciding the content, the quantity and the time of their meals and snacks as well as other lifestyle behaviors such as physical activity and alcohol consumption. $^{22,23}$ The habits formed during youth with regard to composition and quality of the diet, involvement in physical activity and alcohol consumption are influenced by several individual, social and societal factors. $^{21-23}$ They have short-term and long-term influences on health promotion and disease prevention, while it is very probable that they will continue or shape the lifestyle behaviors adopted during adulthood. ${ }^{22}$

Hence, the aim of this study is the assessment of opinions and behaviors related to healthy lifestyle and cancer prevention among Romanian university students.

\section{Materials and Methods}

\section{Study Sample and Procedure for Data Collection}

A cross-sectional study was performed during April and May 2017 and involved 400 university students from the four main universities from Cluj-Napoca — a big university city situated in northwest Romania (University of Medicine and Pharmacy and other three universities who have several faculties, except Medicine and Pharmacy). It used an anonymous questionnaire investigating several issues related to lifestyle.

A convenient sample of students was randomly chosen from eight dorms belonging to the four main universities of the town. This approach was used in order to have access to students from different faculties from the four universities, while contact with those students during their activities in the universities had several logistical constraints. One hundred students (50 girls, 50 boys) living in the selected dorms were randomly chosen from each university. ${ }^{24}$

Students were contacted directly in the dorms by a member of the research team and were informed about the voluntary participation and characteristics of the study. The refusal rate was below $6 \%$ and the students who refused to participate were replaced with students from the same university, living in the same dorm. The participating students filled in the questionnaires which were collected by members of the research team from each room approximately one hour after their distribution. ${ }^{24}$

The study is part of a research project which received the ethical approval of the Ethics Board of University of Medicine and Pharmacy from Cluj-Napoca, Romania.

This study was conducted in accordance with the Declaration of Helsinki.

\section{Instrument for Data Collection}

The study used an anonymous questionnaire developed and tested in previous studies from Romania ${ }^{11,12}$ based on data from literature. ${ }^{1,3,25,26}$ The present study includes information collected through the anonymous questionnaires with regard to sociodemographic characteristics (age, gender, and university), declared weight and height, opinions and behaviors related to cancer prevention.

The investigated behaviors included:

\section{Consumption of Fruits and Vegetables}

It was investigated through two questions regarding how many days they consumed fruits and vegetables fresh or in different meals in the last week, respectively, how many portions of fruits and vegetables they consumed in those days. One portion represents the equivalent of approximately $80 \mathrm{~g}$; for fruit, a serving was defined as a whole fruit (eg, medium apple), three-quarters of a cup $(178 \mathrm{~mL})$ of fruit juice, or half a cup $(120 \mathrm{~mL})$ of cut-up fruit. For 
vegetables, a serving is defined as one cup $(240 \mathrm{~mL})$ raw leafy vegetables (eg, lettuce), half a cup of other vegetables, or three-quarters of a cup of vegetable juice.

\section{Consumption of Red Meat}

It was investigated through two questions regarding how many days they consumed red meat such as beef, pork, lamb, and goat from domesticated animals including that contained in processed food such as sausages, salami, respectively how many portions of red meat consumed in those days. One portion of red meat was defined as a piece of red meat having approximately the size of a deck of cards (around 90-100 g).

\section{Alcohol Consumption}

It was investigated through two questions regarding how many days they consumed alcoholic drinks in the last week, how many drinks were consumed in those days. One portion was defined as one glass of beer $(350 \mathrm{~mL})$, one glass of wine $(150 \mathrm{~mL})$ or one glass of spirits $(40 \mathrm{~mL})$, representing the equivalent of around $10-15 \mathrm{~g}$ of ethanol.

\section{Involvement in Physical Activity}

Participants were asked about the number of days when they were involved in vigorous physical activity (refer to activities that take hard physical effort and make you breathe much harder than normal, such as aerobics, running, fast bicycling, or fast swimming, carrying heavy loads), moderate activity (refer to activities that take moderate physical effort and make you breathe somewhat harder than normal, such as carrying light loads, bicycling at a regular pace, cleaning the house), walking in the last week and how long (in minutes) was the duration of vigorous activity, moderate activity and walking. ${ }^{25}$

Opinions regarding cancer prevention assessed if participants were aware of the relationship between body overweight, vegetables and fruits consumption, red meat consumption, physical activity, alcohol drinking and cancer prevention using a five-point scale for possibilities of answers (from "I totally disagree" to "I totally agree").

Moreover, students were asked their opinion about the quantity of fruits and vegetables and red meat consumed in the last week (possibilities of answers being appropriate, too much, too less, I do not know) as well as their opinion about their weight (possibilities of answers being appropriate, too big, too low, I do not know) and if they have tried to lose or gain weight in the last year.

\section{Data Analyses}

The body mass index (BMI) was computed using the formula $\mathrm{BMI}=$ weight/(heigh $\dot{x}$ height). ${ }^{1,3}$

We calculated the average number of portions of fruits and vegetables consumed per day and the average number of portions of alcohol that they drank per day by multiplying the number of days/week with the number of portions consumed during those days and dividing by seven. At the same time, the average number of portions of red meat consumed per week was computed by multiplying the number of days/week that they consumed it with the number of portions consumed on those occasions.

The number of minutes per week of moderate physical activity (PA) was calculated by summing the number of minutes of intense and moderate PA as well as walking per week. Similar to other studies, ${ }^{3,25}$ we considered that 30 min of vigorous physical activity were equivalent to 60 min of moderate physical activity.

The prevalence of the investigated cancer-related behaviors-BMI, consumption of fruits and vegetables, consumption of red meat, involvement in physical activity and drinking alcohol — was assessed and the 2018 WCRF/AICR Score was used to operationalizes the five behaviors. Two of the behaviors addressed by the 2018 WCRF/AICR Score (limit consumption of "fast foods" and other processed foods high in fat, starches or sugars, and limit consumption of sugar-sweetened drinks) could not be included because the questionnaire did not include information about them. The behavioral score was created for each person by summing the score obtained for the five behaviors.

The factor analysis using the method of principal components with unrotated factor solution was used to recognize major structures regarding cancer prevention-related behaviors (the targeted issues were BMI, consumption of fruits and vegetables, consumption of red meat, physical activity, and alcohol use). Similar to other studies, we considered that the main structures referred to factors with eigenvalues of over 1.5..$^{22,23}$ The regression method was used to measure the scores of factors for every pattern and for each person.

The frequency of the opinions regarding the role of nutrition and physical activity was assessed. The opinion scores were computed by summing the score obtained by one person for all five investigated opinions. Moreover, the level of acknowledgement of the behavioral mistakes was assessed among those with higher BMI, inappropriate consumption of fruits and vegetables as well as red meat. 
Pearson's correlation was used to assess the association between opinion scores, age, gender and the university (participants from the University of Medicine and Pharmacy vs the other students). Moreover, Pearson's correlation was used to evaluate the association between the behavioral score, age, gender, university as well as the opinion scores. At the same time, a similar approach was used for investigating the association between the main cancer preventionrelated structures and the variables mentioned before.

Data analysis was performed with SPSS-20 statistics program. Statistical significance is reported at $p<0.05$.

\section{Results}

\section{Nutritional Patterns and Physical Activity}

As presented in Table 1, 20.8\% of the students are overweight/obese, while around $5 \%$ are underweight. The majority of the students fulfill the recommendations for physical activity of minimum 150 min per week.

Almost all participants do not respect the recommendations of eating a minimum $400 \mathrm{~g}$ of fruits and vegetables and $70 \%$ eat even less than half of the recommended quantity. In contrast, almost half of the students eat more than the recommended quantity of $500 \mathrm{~g} /$ week of red meat. With regard to alcohol consumption one out of three do not respect the recommendations (maximum one drink/day for women and two drink/day for men).

The factor analyses reveal two factors with regard to cancer prevention-related behaviors. The first one consists of those having an appropriate body weight, and having a higher tendency for consumption of fruits and vegetables, performing physical activity, while being more prone not to respect the recommendations regarding the alcohol consumption. In contrast, the second factor refers to a higher tendency to respect the recommendations both for alcohol and red meat consumption (see Table 2).

\section{Nutrition, Physical Activity and Cancer Prevention: Participants' Opinions}

As presented in Table 3 the majority (81\%) of the students are convinced about the role of physical activity in cancer prevention and $73 \%$ recognize the role of alcohol consumption in cancer development.

Around $73 \%$ are convinced about the role of fruits and vegetables in cancer prevention, while one quarter does not know. Moreover, among those who do not eat enough portions of fruits and vegetables $44.5 \%$ believe that the consumed quantity is enough.
Table I Nutritional Patterns and Physical Activity

\begin{tabular}{|c|c|c|}
\hline Issues & $\begin{array}{c}\text { Percentage } \\
\%\end{array}$ & $\begin{array}{l}2018 \text { WCRF/ } \\
\text { AICR Score } \\
\text { Mean (SD) }\end{array}$ \\
\hline $\begin{array}{l}\text { BMI }^{\mathbf{a}} \\
<18.5 \text { (underweight) }\end{array}$ & 5.7 & $0.41(0.15)$ \\
\hline 18.5-24.9 (normal weight) & 73.5 & \\
\hline 25-29.9 (overweight) & 19.3 & \\
\hline$\geq 30$ (obesity) & 1.5 & \\
\hline Physical activity ${ }^{b}$ & & $0.84(0.35)$ \\
\hline$<75 \mathrm{~min} /$ week & 14.2 & \\
\hline $75-<150 \mathrm{~min} /$ week & 2.7 & \\
\hline$\geq 150 \mathrm{~min} /$ week & 83.1 & \\
\hline $\begin{array}{l}\text { Fruits and vegetables } \\
\text { consumption }\end{array}$ & & $0.08(0.13)$ \\
\hline$\leq 200$ g/day ( 2.5 portions) & 69.5 & \\
\hline$>200 \mathrm{~g} /$ day and $<400 \mathrm{~g} /$ day & 27.9 & \\
\hline$\geq 400 \mathrm{~g} /$ day (5 portions) & 2.6 & \\
\hline Red meat consumption ${ }^{d}$ & & $0.26(0.24)$ \\
\hline$\leq 500$ g/week (5 portions) & 52.7 & \\
\hline$>500 \mathrm{~g} /$ week & 47.3 & \\
\hline Alcohol consumption ${ }^{e}$ & & $0.64(0.36)$ \\
\hline 0 drinks & 45.7 & \\
\hline $\begin{array}{l}\leq \mathrm{I} / 2 \text { drinks/day (I for } \\
\text { women, } 2 \text { for men) }\end{array}$ & 16.1 & \\
\hline $\begin{array}{l}>\mathrm{I} / 2 \text { drinks/day (I for } \\
\text { women, } 2 \text { for men) }\end{array}$ & 38.2 & \\
\hline
\end{tabular}

Notes: ${ }^{a}$ Coded according to 2018 WCRF/AICR Score as $\geq 30$ or $<18.5=0$; $25-29.9=0.25$; 18.5-24.9=0.5; information about waist circumference was not available. ${ }^{b}$ Coded according to $2018 \mathrm{WCRF} / \mathrm{AICR}$ Score as $<75 \mathrm{~min} /$ week $=0$; $\geq 75$ and $<150 \mathrm{~min} /$ week $=0.5 ; \geq 150 \mathrm{~min} /$ week $=1$. ' Coded according to $2018 \mathrm{WCRF} / \mathrm{AlCR}$ Score as $\leq 200 \mathrm{~g} /$ day $=0 ;>200 \mathrm{~g} /$ day and $<400 \mathrm{~g} /$ day $=0.25, \geq 400 \mathrm{~g} /$ day ( 5 portions) $=0.5$; information about the quantity of fiber/day was not available. ${ }^{\mathrm{d}}$ Coded according to 2018 WCRF/AICR Score as $>500 \mathrm{~g} /$ week=0; $\leq 500 \mathrm{~g} /$ week=I; *information regarding the consumption of processed meat was not available. ${ }^{e} \mathrm{Coded}$ according to $2018 \mathrm{WCRF} / \mathrm{AlCR}$ Score as $>\mathrm{I} / 2 \mathrm{drinks} / \mathrm{day}=0 ; \leq 1 / 2 \mathrm{drinks} / \mathrm{day}=0.5 ; 0 \mathrm{drinks} /$ day $=$.

Only around one third know about the relationship between red meat consumption and cancer risk, while almost half recognize their lack of knowledge regarding this. At the same time, only $10.5 \%$ of those eating too much red meat are aware of this fact.

Fewer than two thirds of students are convinced about the relationship between excessive weight and cancer. The 
Table 2 The Main Structures Regarding Cancer PreventionRelated Behaviors: Results of Factor Analyses ${ }^{a}$

\begin{tabular}{|l|c|c|}
\hline Issues & Factor I & Factor 2 \\
\hline BMI & 0.7 I & \\
\hline Physical activity & 0.68 & \\
\hline Fruits and vegetables consumption & 0.30 & \\
\hline Red meat consumption & & 0.78 \\
\hline Alcohol consumption & -0.34 & 0.64 \\
\hline
\end{tabular}

Notes: ${ }^{\mathrm{a} F a c t o r}$ loadings higher than 0.30 are depicted.

percentage of those who realized that they are overweight is $65 \%$ and $62 \%$ of the overweight are trying in the last year to lose weight.

\section{Associations Between Opinion Score, Behavioral Score and Other Variables}

The results of the bivariate correlation show that the opinion score was not influenced by age, gender or university, while the behavioral score was higher among girls and those with higher opinion scores. Similar situation was encountered for factor 2, while factor 1 was associated with being students at the University of Medicine and Pharmacy (see Table 4).

Table 3 Opinions About Cancer Prevention ${ }^{\text {a }}$

\begin{tabular}{|l|c|c|c|}
\hline & $\begin{array}{c}\text { I Totally/l } \\
\text { Partially } \\
\text { Agree \% }\end{array}$ & $\begin{array}{c}\text { I Do } \\
\text { Not } \\
\text { Know } \\
\%\end{array}$ & $\begin{array}{c}\text { I Totally/l } \\
\text { Partially } \\
\text { Disagree \% }\end{array}$ \\
\hline $\begin{array}{l}\text { High body weight could } \\
\text { increase the risk of cancer }\end{array}$ & 60.7 & 30.7 & 8.6 \\
\hline $\begin{array}{l}\text { Physical activity could } \\
\text { contribute to cancer } \\
\text { prevention }\end{array}$ & 81.5 & 17.0 & 1.5 \\
\hline $\begin{array}{l}\text { Consumption of fruits and } \\
\text { vegetables could } \\
\text { contribute to cancer } \\
\text { prevention }\end{array}$ & 71.3 & 24.4 & 4.3 \\
\hline $\begin{array}{l}\text { Consumption of red meat } \\
\text { could increase the risk of } \\
\text { cancer }\end{array}$ & 36.6 & 47.7 & 15.4 \\
\hline $\begin{array}{l}\text { Alcohol consumption } \\
\text { could increase the risk of } \\
\text { cancer }\end{array}$ & 73.1 & 16.2 & 9.9 \\
\hline
\end{tabular}

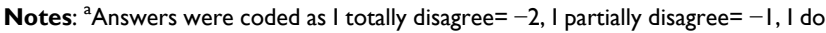
not know $=0$, I partially agree $=+1$, I totally agree $=+2$.
Table 4 Association Between Opinion Score, Behavioral Score and Other Variables: Results of Bivariate Correlation Analyses ${ }^{\mathrm{a}}$

\begin{tabular}{|l|c|c|c|c|}
\hline & $\begin{array}{c}\text { Opinion } \\
\text { Score }\end{array}$ & $\begin{array}{c}\text { Behavioral } \\
\text { Score }\end{array}$ & $\begin{array}{c}\text { Factor } \\
\text { I }\end{array}$ & $\begin{array}{c}\text { Factor } \\
\mathbf{2}\end{array}$ \\
\hline University $^{\mathrm{b}}$ & NS & NS & 0.160 & NS \\
\hline Gender $^{\mathrm{c}}$ & NS & 0.286 & NS & 0.337 \\
\hline Age & NS & NS & NS & NS \\
\hline $\begin{array}{l}\text { Opinion } \\
\text { score }\end{array}$ & - & 0.172 & NS & 0.202 \\
\hline
\end{tabular}

Notes: ${ }^{a}$ Only Pearson coefficients of correlations which are significant are depicted. NS, non-significant. ${ }^{b}$ Coded as $0=$ other universities, I=University of Medicine and Pharmacy. ${ }^{\mathrm{C} C o d e d}$ as $\mathbf{0}=$ boys, $\mathrm{I}=$ girls

\section{Discussion}

This study presents data on the opinions and behaviors of Romanian students with regard to lifestyle and cancer prevention.

The results show that the relationship between being overweight and several types of cancers was recognized by $60 \%$ of the students. Another Romanian study performed in 2011 among adults having relatives with cancer showed that the fact that being overweight might increase the risk for several cancers was recognized by $45 \%$ of the participants, with people from urban areas being more aware of this. ${ }^{12}$ One out of five university students from our study were overweight or obese, with obesity being present among fewer than $2 \%$ of the participants. Another study performed in 2016 among Romanian university students showed similar results, while the prevalence of being overweight/obese was more than double among older adults, as proved by another Romanian study. ${ }^{11,22}$ Moreover, in our study two thirds of overweight students recognize that their weight is higher than it should be and $62 \%$ were trying to lose weight in the last year, showing the need for appropriate education and counselling measures and services for body weight management among university students.

A percentage of $71 \%$ of our study participants recognized the protective effect of fruit and vegetable consumption against cancer; similar results were obtained by the previous study performed among Romanian adults having relatives with cancer. ${ }^{12}$ Nevertheless, almost all do not fulfil the recommendations of eating $400 \mathrm{~g}$ fruits and vegetables daily and two thirds are eating less than 200 $\mathrm{g}$ per day. One reason might be the fact that they do not know the recommendations, almost half of the participants believing they eat enough. Other studies from Romania 
also underlined the insufficient amount of fruits and vegetables consumed by different population groups, calling for research and health promotion measures in order to increase fruits and vegetables consumption. ${ }^{11,22,27-29}$

The risk of consuming red meat and cancer have got the lowest percentage of people who agree with this (around one third), while almost half recognize that they do not know about this issue. In the study performed among Romanian adults having relatives with cancer half of the participants knew the link between the consumption of red meat and cancer; older people, those with a higher educational level and those living in urban areas were more aware of it. ${ }^{12}$ Moreover, in our study $47 \%$ of the participants eat more than $500 \mathrm{~g}$ of red meat per week; similar results were also found in the study performed among older Romanian adults. ${ }^{11}$ As for fruits and vegetables, one reason might be the fact that they do not recognize the recommendations, only $10 \%$ of those eating too much recognize this. Once again, our study shows that these recommendations for limiting the consumption of red meat remain insufficiently known by several population groups and as a consequence lead to overconsumption by many participants. This situation is influenced by other factors such as gastronomic cultural habits and accessibility (pork is traditionally the meat most frequently consumed in this region of Romania, while the accessibility and attractiveness because of price, taste, ease of use of different processed meat products such as salami, sausages is also high). ${ }^{22,27}$

With regard to the risk of alcohol consumption for different types of cancer $73 \%$ recognize this, the percentage being similar to that obtained among adults having relatives with cancer. ${ }^{12}$ Thirty-eight percent of the students drink more than the recommended portions of drinks/day, the percentage being higher compared with results performed among older adults. ${ }^{11}$

The protective effect of physical activity for cancer was admitted by the majority of students $(81.5 \%)$, the percentage being higher than in the study performed among adults having relatives with cancer where this relationship was recognized by two thirds of the study sample, people from urban areas and those having a higher educational level being more aware. ${ }^{12}$ At the same time, more than $80 \%$ of the students respect the recommendations of physical activity/week, which is the strength of this population group, while other groups of adults perform less with respect to this issue. ${ }^{11}$ The importance of PA for prevention of chronic diseases was highlighted by different educational activities, including mass media campaigns in Romania, while this age group seems particularly interested in being physically active and fit.

Several studies underline that healthy or unhealthy diet, physical activity, and weight-related behaviors often do not occur in isolation and are correlated with each other in different ways with a possible synergetic effect of multiple health behaviors on the risk of cancer, chronic conditions and other health outcomes. ${ }^{22,30,31,32}$

Our study shows that there are two factors with regard to cancer prevention-related behaviors. The first one comprises having an appropriate BMI as well as having better consumption of fruits and vegetables and performing the recommended time for PA, but these combine with a tendency for inappropriate alcohol consumption. The other factor refers to having a stronger tendency to respect the recommendations regarding red meat consumption and alcohol consumption.

No age and gender differences were found with regard to opinion scores, but girls scored higher with regard to behavioral score and it is noticed that the tendency of belonging to the female group is associated with factor two.

Students from the University of Medicine and Pharmacy did not score higher for opinions or behavioral scores, but factor one was more frequent among this group. Students with higher opinion scores had also a higher behavioral score and were more frequent among the group from the factor two.

This study is subject to several limitations: it has a cross-sectional design and a limited sample of Romanian university students from Cluj-Napoca, some of the information from the 2018 WCRF/AICR Score was not evaluated by this study performed in 2017, while weight and height were not measured and rely on students' own perception.

\section{Conclusions}

This is the first study from Romania looking into knowledge, attitudes and behavior of students with regard to the role of diet and physical activity for cancer prevention. It underlines that this group has good level of knowledge with regard to the importance of some factors for cancer prevention (physical activity, alcohol consumption), but the translation of this knowledge into practice varies, with involvement on PA being the recommendation best 
accepted. The level of knowledge for the role of alimentary habits is moderate for fruits and vegetables (they recognize their importance, but do not know how much they should eat) or even low for red meat consumption. Nevertheless, the recommendations are not respected by many students with regard to these two alimentary behaviors. The role of BMI is recognized to quite a high extent and students are preoccupied by maintaining an appropriate BMI, with one out of five being overweight, while many of these overweight students are trying to lose weight.

Compared with older Romanian adults, university students seems to perform better with regard to PA involvement and BMI, similarly with regard to fruits and vegetables consumption and red meat consumption and worst regarding drinking alcohol, possibly related to the developmental phase they are passing through. ${ }^{11,22,31,32}$

Future educational activities should focus on promoting better nutritional habits, decrease alcohol consumption and offer appropriate services for weight management among Romanian university students.

\section{Institutional Review Board Statement}

The study is part of a research project which received the ethical approval (120/6.03.2015) of the Ethics Board of University of Medicine and Pharmacy from Cluj-Napoca, Romania.

\section{Informed Consent Statement}

Informed consent was obtained from all subjects involved in the study. Students who did not want to participate did not fill in the anonymous questionnaire.

\section{Author Contributions}

All authors made substantial contributions to conception and design, acquisition of data, or analysis and interpretation of data; took part in drafting the article or revising it critically for important intellectual content; agreed to submit to the current journal; gave final approval of the version to be published; and agree to be accountable for all aspects of the work.

\section{Funding}

This research received no external funding.

\section{Disclosure}

The authors report no conflict of interest in this work.

\section{References}

1. World Health Organization. Global action plan for the prevention and control of noncommunicable diseases 2013-2020. Geneva: World Health Organization; 2013.

2. World Health Organizations. A guide to implementation research in the prevention and control of noncommunicable diseases. World Health Organization: Geneva; 2016.

3. World Cancer Research Fund/American Institute for Cancer Research. Food, nutrition, physical activity, and the prevention of cancer: A global perspective. AICR: Washington DC; 2007.

4. World Cancer Research Fund/American Institute for Cancer Research. Diet, nutrition, physical activity, and cancer: A global perspective. AICR: Washington DC; 2018.

5. Marissa SWM, Nigel BT, Panagiota M, et al. Operationalizing the 2018 World Cancer Research Fund/American Institute for Cancer Research (WCRF/AICR) cancer prevention recommendations: A standardized scoring system. Nutrients. 2019;11:1572. doi:10.3390/nu11071572

6. Solans M, Chan DSM, Mitrou O, et al. A systematic review and meta-analysis of the $2007 \mathrm{WCRF} / \mathrm{AICR}$ score in relation to cancer-related health outcomes. Ann Oncol. 2020;31:352-368. doi:10.1016/j.annonc.2020.01.001

7. Costa AR, Silva S, Moura-Ferreira P, et al. Health-related knowledge of primary prevention of cancer in Portugal. Eur J Cancer Prevent. 2016;25(1):50-53. doi:10.1097/CEJ.0000000000000125

8. Falzon C, Chalabaev A, Schuft L, et al. Beliefs about physical activity in sedentary cancer patients: An in-depth interview study in France. Asian Pacific J Cancer Prevent. 2012;13(12):6033-6038. doi:10.7314/APJCP.2012.13.12.6033

9. Humpel N, Magee C, Jones SC. The impact of a cancer diagnosis on the health behaviors of cancer survivors and their family and friends. Supportive Care Cancer. 2007;15(6):621-630. doi:10.1007/s00520006-0207-6

10. Gavrilas LI, Ionescu C, Balacescu O, et al. Foods and food groups associated with colorectal cancer: a case-control study. Farmacia. 2018;66(5):846-852. doi:10.31925/farmacia.2018.5.15

11. Lotrean LM, Ailoaiei R, Torres-Mejia G. Health risk behavior of Romanian adults having relatives with cancer. Asian Pacific $J$ Cancer Prevent. 2013;14(11):6465-6468. doi:10.7314/ APJCP.2013.14.11.6465

12. Lotrean LM, Ailoaiei R, Torres-Mejia G, Popa M. The role of lifestyle in cancer prevention: opinions of Romanian cancer patients' relatives. Palestrica Third Millennium Civilization Sport. 2015;16 (1):11-16.

13. Barrios Rodriques R, Toledo E, Martinez Gonzales $M$, et al. Adherence to the 2018 World Cancer Research Fund/American Institute for Cancer Research recommendations and breast cancer in the SUN project. Nutrients. 2020;12:2076. doi:10.3390/nu12072076

14. Turati F, Dalmartello M, Bravi F, et al. Adherence to the World Cancer Research Fund/American Institute for Cancer Research recommendations and the risk of breast cancer. Nutrients. 2020;12 (3):607. doi:10.3390/nu12030607

15. Olmedo-Requena R, Lozano-Lorca M, Salceda Bellido M, et al. Compliance with the 2018 World Cancer Research Fund/American Institute for Cancer research cancer prevention recommendations and prostate cancer. Nutrients. 2020;12:768. doi:10.3390/nu12030768

16. Hakime NN, Cil AA, Havva S, et al. Dietary habits contributing to the cancer prevention among health college students in Turkey. Asian Pacific J Cancer Prevent. 2012;13:963-968. doi:10.7314/ APJCP.2012.13.3.963 
17. Ahmed ANR, Chen R. Nutrition and cancer prevention: knowledge, attitudes and practices among young Malaysians. Asian Pacific $J$ Cancer Prevent. 2011;12:691-694.

18. Ayden C, Oya K, Ferda O. The evaluation of school of health students 'knowledge and behavior of healthy life-styles of related to importance to prevent cancer. Asian Pacific J Cancer Prevent. 2010;11:773-776.

19. Murat B, Tuna AM, Sami AY, et al. Turkish university students` nutritional habits regarding cancer prevention and healthy lifestyles. Asian Pacific J Cancer Prevent. 2010;11:1347-1350.

20. Ha EJ, Caine-Bish N. Effect of nutrition intervention using a general nutrition course for promoting fruit and vegetable consumption among students. J Nutr Educ Behav. 2009;41:103-109. doi:10.1016/ j.jneb.2008.07.001

21. Folasire FO, Folasire MA, Chikezie S. Nutrition-related cancer prevention knowledge of undergraduate students at the University of Ibadan, Nigeria. South Afr J Clin Nutr. 2016;29:165-171. doi:10.1080/16070658.2016.1217648

22. Lotrean LM, Stan O, Lencu C, Laza V. Dietary patterns, physical activity, body mass index, weight-related behaviours and their interrelationship among Romanian university students - trends from 2003 to 2016. Nutricion Hospitalaria. 2018;35(2):375-383. doi:10.20960/ nh.1296

23. Yang Y, Hu XM, Chen TJ, et al. Rural-urban differences of dietary patterns, overweight, and bone mineral status in Chinese students. Nutrients. 2016;8:537. doi:10.3390/nu8090537

24. Lotrean LM, Milena M, Gavrilescu C, Florea M. Electronic cigarette use and its relationship with smoking and alcohol and illicit drug consumption among Romanian university students. MedicinaLithuania. 2021;57(2):137.
25. Bauman A, Ainsworth BE, Bull F, et al. Progress and pitfalls in the use of the International Physical Activity Questionnaire (IPAQ) for adult physical activity surveillance. J Physical Activity Health. 2009;6:5-8. doi:10.1123/jpah.6.s1.s5

26. Bauman AB, Chey T, Craig CL. The IPS group the international prevalence study on physical activity: results from 20 countries. Int J Behav Nutr Phys Activity. 2009;31:21. doi:10.1186/1479-5868-6-21

27. Lotrean LM, Laza V, Ionut C. Factors which influence food choice and food habits of Romanian young people. In: Consumer and Nutrition. Challenges and Chances for Research and Society. 9th Karlsruhe Nutrition Congress, October 10-12, 2004. Karlsruhe: Berichte der Bundesforschungsanstalt für Ernährung und Lebensmittel; 2005.

28. Lotrean LM, Tutui I. Individual and familial factors associated with fruit and vegetable intake among 11- to 14-year-old Romanian school children. Health Soc Care Community. 2015;23(5):541-549. doi:10.1111/hsc. 12166

29. Lupșa T, Lotrean LM. Consumption of fruits and vegetables among secondary school students from Cluj county. J School Univ Med. 2019;6(3):21-26.

30. López ML, Iglesias JM, Del Valle MO, et al. Impact of a primary care intervention on smoking, drinking, diet, weight, sun exposure, and work risk in families with cancer experience. Cancer Cause Control. 2007;18(5):525-535. doi:10.1007/s10552-007-0124-0

31. Alzahrani S, Saeedi A, Baamer MK, Shalabi AS, Alzahrani A. Eating habits among medical students at King Abdulaziz University, Jeddah, Saudi Arabia. Int J Gen Med. 2020;13:77-88. doi:10.2147/IJGM. S246296

32. Lotrean L, Popa M, Santillan EA, Florea M. Methodological challenges in research regarding the lifestyle of school children. Revista De Cercetare Si Interventie Sociala. 2014;44:321-331.
International Journal of General Medicine

\section{Publish your work in this journal}

The International Journal of General Medicine is an international, peer-reviewed open-access journal that focuses on general and internal medicine, pathogenesis, epidemiology, diagnosis, monitoring and treatment protocols. The journal is characterized by the rapid reporting of reviews, original research and clinical studies across all disease areas. The manuscript management system is completely online and includes a very quick and fair peer-review system, which is all easy to use. Visit http://www.dovepress.com testimonials.php to read real quotes from published authors. 